\title{
Mental Health 15 Years After the Killings in Rwanda: Imprisoned Perpetrators of the Genocide Against the Tutsi Versus a Community Sample of Survivors
}

\author{
Susanne Schaal, ${ }^{1}$ Roland Weierstall, ${ }^{1}$ Jean-Pierre Dusingizemungu, ${ }^{2}$ and Thomas Elbert ${ }^{1}$ \\ ${ }^{1}$ Department of Psychology, University of Konstanz, Konstanz, Germany \\ ${ }^{2}$ Department of Psychology, University of Butare, Butare, Rwanda
}

\begin{abstract}
Objectives of this study were to compare rates of mental health disorders in Rwandan genocide perpetrators with those of genocide survivors and to investigate potential predictors of symptoms of posttraumatic stress disorder (PTSD) and depression for both groups. We expected high rates of mental disorders in both study groups and hypothesized that symptom severity would be predicted by female gender, older age, lower level of education, higher level of trauma exposure, lower level of agreement to reconciliation, and the participation in killing. Structured clinical interviews were carried out with 269 imprisoned perpetrators (66\% men) and 114 survivors (64\% women). Significantly more survivors than perpetrators met symptom criteria for PTSD (46\% vs. $14 \%$ ) and suffered from anxiety symptoms (59\% vs. 36\%). A substantial proportion of both groups suffered from clinically significant depression (46\% vs. 41\%). PTSD severity in perpetrators was associated with trauma exposure, high levels of agreement to reconciliation, and no participation in killing; the severity of depression was associated with trauma exposure and no participation in killing. In the survivor sample, the severity of PTSD and depression were both correlated with female gender, trauma exposure, and low levels of agreement to reconciliation. Results suggest that both groups exhibit considerable psychiatric morbidity.
\end{abstract}

During the Rwandan genocide of 1994, between 800,000 and $1,000,000$ Rwandese were killed within a period of 3 months. Fighting erupted between two artificially divided ethnic groups, the Hutu majority and the Tutsi minority. The main goal of the perpetrators of the genocide was the extermination of the Tutsi minority and the Hutu opponents. Over $10 \%$ of the total Rwandan population was eliminated. Many people, including ordinary citizens, joined the slaughter, either willingly or under coercion. According to Scherrer (1997), 25\% of the Hutu population (including children and women) directly participated in the perpetration of the Rwandan genocide.

Previous studies have documented the extreme degree of traumatic exposure, including losses suffered by Rwan-

Research was funded by the Deutsche Forschungsgemeinschaft (German Research Foundation). We would like to thank the respondents for their trust and openness and the prison staff in Butare and Kigali for their support. We thank Inga Schalinski, Heike Riedke, and the following Rwandan psychologists for their help in data collection: Pierre Bisengimana, Emmanuel Hakizimana, Ernest Hakizimana, Felix Harindintwari, Charles Ingabire, Peace Kabihogo, Télesphore Nambajimana, Agnes Nyirabizimana, Anatole Nzabakurana, and Léopold Rwemeraturame.

Correspondence concerning this article should be addressed to Susanne Schaal, University of Konstanz, Department of Psychology, Universitätsstrasse 10, 78457 Konstanz, Germany. E-mail: Susanne.Schaal@gmx.de dan genocide survivors (Neugebauer et al., 2009; Schaal \& Elbert, 2006). Studies with different community samples have demonstrated that symptoms of posttraumatic stress disorder (PTSD; Brounéus, 2010; Schaal \& Elbert, 2006; Schaal, Elbert, \& Neuner, 2009a), depression (Brounéus, 2010), and prolonged grief disorder (PGD; Schaal, Elbert, \& Neuner, 2009b; Schaal, Jacob, Dusingizemungu, \& Elbert, 2010) are highly prevalent in this population. To the best of our knowledge, no study has yet investigated the mental health of Rwandan genocide perpetrators. It is known, however, that participation in mass violence - and particularly in killing - may be considered as a traumatic event that may also cause traumarelated symptoms (McNair, 2002; Staub, 2006). The infliction of harm upon others can be considered as a traumatic event, especially when, as was the case in Rwanda, extreme pressure was exerted on the perpetrators (Aguilar, 1998). The first goal of the study was thus to examine the mental health of Rwandan genocide survivors and perpetrators.

Massive arrests followed the Rwandan genocide. To deal with the thousands of prisoners accused of genocide-related crimes, a traditional Rwandan community-based conflict resolution system called "Gacaca" was introduced in 2005. The idea that a perpetrator's confession could lead to forgiveness and reconciliation was incorporated as a key element into the Gacaca process. According to Staub (2006), reconciliation means that survivors and perpetrators accept each other and see the possibility of a constructive relationship. Similarly, Kohen, Zanchelli, and 
Drake (2011) stress the importance of a normative interaction between the Rwandan ethnic opponents during the process of reconciliation based on the mutual acceptance of both groups as distinct but equal members of the community. Reconciliation is a preventative action in avoiding new violence and has a special effect in Rwanda, where both groups continue to live together (Staub, 2006). Research suggests that a number of factors have a significant impact on the readiness to reconcile, including the perception of justice and truth (Staub \& Pearlman, 2006), forgiveness and trust (Glas, 2006), empathy (McCullough, Worthington, \& Rachal, 1997), and a lack of mental health problems (Bayer, Klasen, \& Adam, 2007; Witvliet, Phipps, Feldmann, \& Beckham, 2004).

A second goal of the present study was to explore variables associated with mental health in survivors and perpetrators. We investigated the following correlates of symptom severity of PTSD and depression in genocide survivors and perpetrators: gender, age, level of education, level of trauma exposure, attitudes towards reconciliation, and for perpetrators, participation in killing.

In terms of demographic variables, female gender is a commonly reported risk factor in the development of symptoms of depression and PTSD (Brewin, Andrews, \& Valentine, 2000; DiGrande et al., 2008; Thapa \& Hauff, 2005). Age and level of education are inconsistently reported risk factors: Whereas some studies found an older age (Marshall, Schell, Elliott, Berthold, \& Chun, 2005) and lower level of education (Basile, Arias, Desai, \& Thompson, 2004; Brewin et al., 2000) to be associated with the development of mental health problems, other authors documented no such associations for the demographic variables of age (Basile et al., 2004) or level of education (Schaal, Jacob, Dusingizemungu, \& Elbert, 2011).

A large number of studies have found a dose-response relationship between cumulative trauma exposure and the development of mental health problems (Neugebauer et al., 2009; Schaal \& Elbert, 2006; for a review, see March, 1993). Several researchers have shown that symptom severity of PTSD was associated with less openness to reconciliation and more feelings of revenge (Bayer et al., 2007; Witvliet et al., 2004).

People who participate in killings often tend to be traumatized by their own actions and may develop symptoms of PTSD (McNair, 2002; Staub, 2006). Other researchers have reported that a protective mechanism may prevent the perpetrator from developing severe mental health problems (Elbert, Weierstall, \& Schauer, 2010; Nadelson, 1992). We examined whether participation in killings would entail fewer severe mental health problems in perpetrators compared to those who did not actively participate in killings.

The primary goal of the present study was to examine mental health in a sample of Rwandan genocide perpetrators and survivors. We expected high rates of mental disorders in both study groups. A secondary goal was to describe the potential associations of symptoms of PTSD and depression in these imprisoned perpetrators and survivors. We hypothesized that the severity of PTSD and depression in both groups would be associated with female gender, older age, lower level of education, higher level of trauma exposure, lower level of agreement to reconciliation, and for perpetrators, the participation in killing.

\section{Method}

\section{Participants and Procedure}

Eligible participants were survivors and perpetrators of the Rwandan genocide who were at least 18 years old during the genocide in 1994 and who had experienced the genocide. Genocide survivors were participants who had never been accused of or sentenced for any genocide-related crimes. Genocide perpetrators were participants who were accused of or sentenced for genocide-related crimes and who were imprisoned at the time of the interview at the national prison of Butare or $\mathrm{Ki}$ gali. In total, 269 genocide perpetrators and 114 genocide survivors were interviewed for this study. Twelve subjects who were approached refused to participate in the trial. The imprisoned perpetrator sample consisted of 92 women (34.2\%) and 177 men $(65.8 \%)$; the survivor sample consisted of 72 women $(63.7 \%)$ and 41 men $(36.3 \%)$. The mean age was 48.45 years (interquartile range $[\mathrm{IQR}]=40.0-55.5$ ) for the perpetrators, and 46.56 years (IQR $=36.0-53.3$ ) for the survivors. As the primary goal of the genocide was the complete extermination of men, the majority of survivors in Rwanda are women; and as more men have committed serious offenses during the genocide, there are more men than women imprisoned. The random selection reflects this gender imbalance in both samples. Further characteristics of the sample can be drawn from Table 1. There were significant between-group differences in the variables of age $(U=13,239, p=.034)$, gender $\chi^{2}(1, N=383)=$ 28.30, $p<.001$, and the highest school degree obtained $(U=$ $11,241.50, p<.001)$.

The study was conducted in Butare and Kigali, Rwanda in February and March 2009. It was approved by the University of Konstanz Ethical Review Board, the Rwandan Ministry of Science and Technology, and the Ministry of Internal Security/Rwanda Prisons Service. All participants were fully informed of the study's procedure and aims, including voluntary participation and provided us their signed written informed consent. Perpetrators were informed that the interviewers operated independently of the prison system and no one associated with the prison system was allowed access to the collected data. Diagnostic interviews were carried out by 10 master'slevel psychologists from the National University of Butare, Rwanda, and with the help of well-trained interpreters, by five clinical psychologists from the University of Konstanz, Germany. All local raters had already received extensive training in conducting structured diagnostic interviews and the various questionnaires had already been translated into Kinyarwanda as a part of previous studies (Schaal et al., 2010). Certain prisonspecific questions and criminological characteristics as well as 
Table 1

Demographic Characteristics of and Mental Health in Rwandan Genocide Perpetrators and Survivors

\begin{tabular}{|c|c|c|c|c|c|c|c|c|}
\hline \multirow[b]{2}{*}{ Variable } & \multicolumn{4}{|c|}{ Perpetrators $(n=269)$} & \multicolumn{4}{|c|}{ Survivors $(n=114)$} \\
\hline & $n$ & $\%$ & $M$ & $I Q R$ & $n$ & $\%$ & $M$ & $I Q R$ \\
\hline \multicolumn{9}{|l|}{ Sex } \\
\hline Male & 177 & 65.8 & - & - & 41 & 36.3 & - & - \\
\hline Female & 92 & 34.2 & - & - & 72 & 63.7 & - & - \\
\hline \multicolumn{9}{|l|}{ School degree } \\
\hline No degree & 177 & 66.0 & - & - & 45 & 39.8 & - & - \\
\hline Primary school & 68 & 25.4 & - & - & 53 & 46.9 & - & - \\
\hline Secondary school & 13 & 4.9 & - & - & 4 & 3.5 & - & - \\
\hline Apprenticeship & 6 & 2.2 & - & - & 11 & 9.7 & - & - \\
\hline University & 4 & 1.5 & - & - & - & - & - & - \\
\hline \multicolumn{9}{|l|}{ Religion } \\
\hline Catholic & 144 & 53.5 & - & - & 59 & 51.8 & - & - \\
\hline Protestant & 75 & 27.9 & - & - & 41 & 36.0 & - & - \\
\hline Islamic & 15 & 5.6 & - & - & 2 & 1.8 & - & - \\
\hline Adventiste & 26 & 9.7 & - & - & 12 & 10.5 & - & - \\
\hline Other & 5 & 1.9 & - & - & - & - & - & - \\
\hline No religion & 4 & 1.5 & - & - & - & - & - & - \\
\hline \multicolumn{9}{|l|}{ Interviewer } \\
\hline Locals & 203 & 75.5 & - & - & 87 & 76.3 & - & - \\
\hline Experts & 66 & 24.5 & - & - & 27 & 23.7 & - & - \\
\hline PTSD Diagnosis & 36 & 13.5 & - & - & 52 & 46.4 & - & - \\
\hline PTSD severity score & - & - & 6.06 & $0.0-9.0$ & - & - & 14.61 & $6.8-23.0$ \\
\hline Syndromal depression & 111 & 41.4 & - & - & 51 & 46.4 & - & - \\
\hline Depression score & - & - & 25.50 & $18.0-31.0$ & - & - & 26.65 & $18.0-34.0$ \\
\hline Syndromal anxiety & 96 & 35.8 & - & - & 66 & 58.9 & - & - \\
\hline Anxiety score & - & - & 16.31 & $11.0-20.8$ & - & - & 19.93 & $13.0-26.0$ \\
\hline Suicide risk & 50 & 18.6 & - & - & 22 & 19.3 & - & - \\
\hline
\end{tabular}

Note. $N=383 . \mathrm{PTSD}=$ Posttraumatic stress disorder; $\mathrm{IQR}=$ interquartile range.

questions about reconciliation were translated into Kinyarwanda and blind-reverse translated by independent groups of master's-level psychology students from the University of Butare. Interviews with genocide perpetrators were carried out individually in private rooms at the national prisons of Butare or Kigali. Researchers informed prison staff about the aforementioned inclusion criteria and perpetrators were randomly selected from a complete list of inmates. Interviews with genocide survivors were conceived of as a community-based study in randomly selected sectors of Butare (Rusatira, Kinazi Sogwe, Mbazi) and Kigali (Nyarugunga). Interviewers went door-todoor, starting at a convenient location within the assigned quarter of the sector and approached each subsequent house. If more than one dweller met inclusion criteria, two survivors were randomly selected for participation. After the interview, genocide survivors were reimbursed 1,000 Rwandan Francs (about 1.30 Euro) for their participation. Interviews lasted about 2 hours for both study samples.

\section{Measures}

Interviewers obtained sociodemographic data from each respondent. Ethnicity was not asked as it is illegal to collect this type of information in Rwanda. Interviewers measured traumatic events using the modified Event-Scale from Schaal and Elbert (2006) and assessed exposure to 26 different traumatic event types. Interviewers asked if the person had committed any of 16 different types of crimes. This list also included questions about the participation in murder (either killing and/or participation in a massacre). The variable "participation in murder" was derived by merging these two offenses. We assessed attitudes towards the concept of reconciliation using 16 items that examined attitudes toward forgiveness, future orientation, empathy, trust, justice, revenge, and the use of violence. Previous studies in this field have described these as some of the key elements within the concept of reconciliation (Glas, 2006; McCullough et al., 1997; Staub \& Pearlman, 2006; see Table 2). Respondents answered each of these items according 
Table 2

Percentage Endorsing Attitudes Towards Reconciliation in Perpetrators and Survivors

\begin{tabular}{|c|c|c|c|c|c|c|}
\hline \multirow[b]{2}{*}{ Abbreviated item } & \multicolumn{3}{|c|}{ Perpetrators $(n=269)$} & \multicolumn{3}{|c|}{ Survivors $(n=114)$} \\
\hline & A & $\mathrm{N}$ & $\mathrm{D}$ & A & $\mathrm{N}$ & $\mathrm{D}$ \\
\hline I experience feelings of revenge. & 2.6 & 0.7 & 96.7 & 3.5 & 0.9 & 95.6 \\
\hline Most perpetrators don't regret. & 35.7 & 20.8 & 43.5 & 57.5 & 13.3 & 29.2 \\
\hline I don't trust anyone. & 40.5 & 11.9 & 47.6 & 28.9 & 18.4 & 52.6 \\
\hline The use of violence to resolve conflicts is justified. & 47.2 & 3.7 & 49.1 & 43.0 & 1.8 & 55.3 \\
\hline Perpetrators feared consequences. & 68.0 & 16.0 & 16.0 & 42.9 & 18.8 & 38.4 \\
\hline It's important that victims of war receive restitution. & 88.1 & 5.6 & 6.3 & 93.0 & 5.3 & 1.8 \\
\hline One day we will all be able to live together in harmony. & 91.8 & 4.5 & 3.7 & 78.9 & 9.6 & 11.4 \\
\hline We are all depending on each other. & 94.1 & 2.2 & 3.7 & 82.5 & 7.0 & 10.5 \\
\hline Persons who harmed others should be treated fairly. & 95.2 & 2.6 & 2.2 & 93.8 & 3.5 & 2.7 \\
\hline We should focus on future instead of past. & 95.5 & 3.0 & 1.5 & 96.5 & 1.8 & 1.8 \\
\hline Even perpetrators might have experienced painful events. & 95.5 & 1.9 & 2.6 & 70.8 & 14.2 & 15.0 \\
\hline Everyone should be judged according to the same rights. & 95.5 & 1.9 & 2.6 & 93.9 & 3.5 & 2.6 \\
\hline One should forgive one's enemy. & 96.6 & 1.9 & 1.5 & 84.1 & 5.3 & 10.6 \\
\hline I am ready for a new beginning. & 89.2 & 5.6 & 5.2 & 92.1 & 4.4 & 3.5 \\
\hline It's important persons have a common future goal in mind. & 98.5 & 0.7 & 0.7 & 99.1 & 0.0 & 0.9 \\
\hline We should decide to live in peaceful coexistence. & 98.9 & 0.0 & 1.1 & 93.9 & 2.6 & 3.5 \\
\hline
\end{tabular}

Note. For clearer representation of the data, the two response categories strongly agree and agree were merged into $\mathrm{A}=$ agree; strongly disagree and disagree into $\mathrm{D}=$ disagree; $\mathrm{N}=$ neutral.

to a 5-point scale ranging from $0=$ totally disagree to $4=$ totally agree, representing increasing levels of agreement. Reliability was modest, showing moderate homogeneity for all 16 items (Cronbach's $\alpha=.60)$. A reconciliation-attitude score was the sum of all 16 items (possible scores range from 0-64; items $5,13,14$, and 15 were reversed for purposes of scoring).

We assessed diagnostic status and symptom severity of PTSD using the PTSD Symptom Scale-Interview (PSS-I, possible scores range from 0-51; Cronbach's $\alpha=.92$; Foa \& Tolin, 2000). Symptoms of anxiety and depression were measured with the Hopkins Symptom Checklist-25 (HSCL-25; Derogatis, Lipman, Rickels, Uhlenhut, \& Covi, 1974). Each of the 10 and 15 items measuring anxiety and depression are scored on a 4-point response scale $(1=$ not at all bothered; 2 = a little bothered; 3 = quite a bit bothered; $4=$ extremely bothered). Possible scores for the anxiety score range from 10 to 40 (Cronbach's $\alpha=.88$ ) and for the depression score from 15 to 60 (Cronbach's $\alpha=.87$ ). A mean score of 1.75 (sum score divided by the number of items) was defined as the cut-off point for syndromal depression and anxiety (Mollica, Wyshak, de Marneffe, Khuon, \& Lavelle, 1987). The scale for suicidality from the Mini-International Neuropsychiatric Interview (M.I.N.I.; Sheehan et al., 1998) was used to assess risk of suicidality (Cronbach's $\alpha=.67$ ).

\section{Data Analysis}

The presented descriptive data are expressed as frequencies $(\%)$, mean scores, and IQRs. To investigate the association between mental health and different independent variables, linear regression analyses were calculated for the PTSD severity score and the depression score. The following variables were simultaneously entered in the analyses: gender, age, any school degree obtained (yes/no), number of types of lifetime traumatic events, the reconciliation-attitude score, and participation in murder (the last variable was entered into the analyses with the perpetrator sample as a dichotomous variable). Data analysis was conducted using SPSS software, Version 19. The reported statistical tests were two-tailed.

\section{Results}

Both groups were exposed to a wide range of traumatic events. There was a significant difference in the number of traumatic events between survivors, $M=14.40$, IQR $=12.0-17.0$, range $=4-22$, and perpetrators, $M=9.98, \mathrm{IQR}=8.0-13.0$, range $=$ $1-22, t(378)=-10.61, p<.001$.

The majority of perpetrators $(89.6 \%, n=241)$ had been convicted; the remaining $10.4 \%(n=28)$ were accused of genocide-related crimes and were still waiting for their conviction or trial. Perpetrators had spent an average of 7.45 years in prison $(I Q R=2.0-13.0$, range $1-15)$. Within the imprisoned perpetrator sample, $88.4 \%(n=236)$ had had a Gacaca trial and $8.0 \%(n=20)$ underwent a national lawsuit. Almost all perpetrators $(96.9 \%, n=186)$ indicated that their Gacaca trial took place in 2006 or later. Perpetrators had been accused of or convicted for a wide range of offences; the main ones included murder $(25.5 \%, n=67)$, participation in a massacre $(14.3 \%$, 


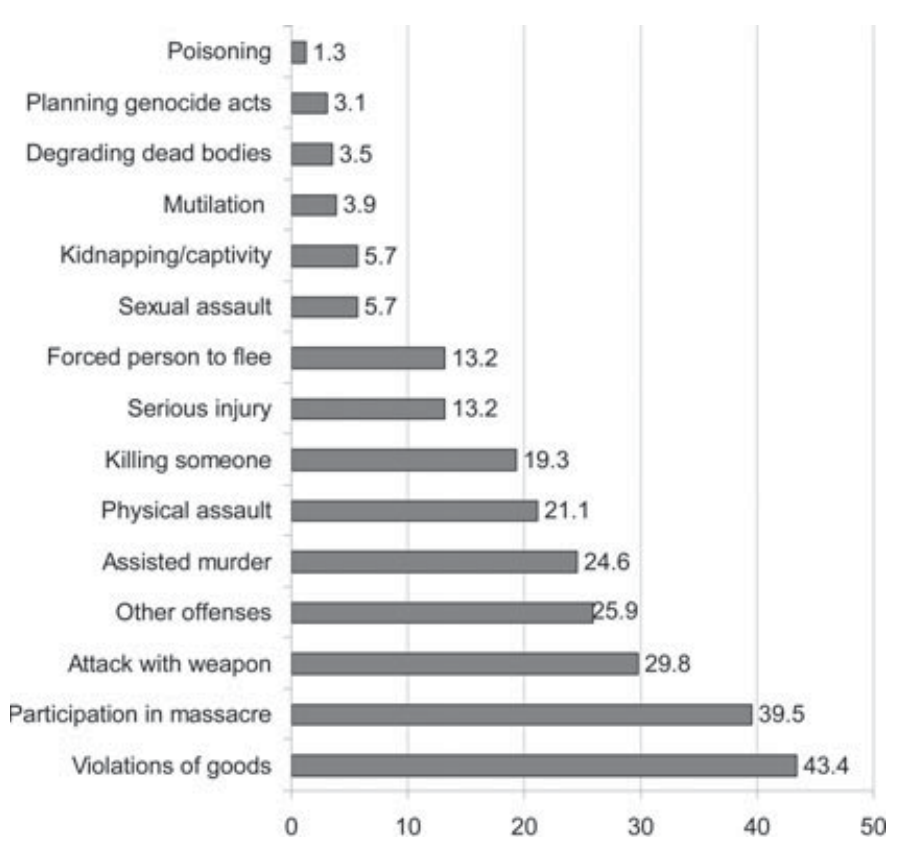

Figure 1. Committed offenses of prisoners in percentages $(n=228)$.

$n=38)$, sexual assault $(12.5 \%, n=33)$, assisted murder (20.4\%, $n=55)$, and other offenses (13.0\%, $n=35$; categories of less than $10 \%$ are not reported here).

The sentences of those who had been convicted ranged from 1 year to life in prison: Twelve percent $(n=29)$ had been sentenced to $1-10$ years, $43.4 \%(n=104)$ to $11-20$ years, $25.0 \%(n=60)$ to $21-30$ years, and $19.6 \%(n=47)$ to life imprisonment. The majority of perpetrators $(84.8 \%, n=228)$ reported having committed at least one offense during their lifetime. A minority $(14.9 \%, n=40)$ indicated that they had never committed any offense and that they had been falsely accused or convicted. Figure 1 summarizes the offenses of those perpetrators who had admitted to committing a crime $(n=$ $228)$. Of those, $38.2 \%(n=87)$ indicated the participation in murder, but a minority reported the murder offense as their most distressing event $(12.6 \%, n=11)$. They reported a mean of 2.55 of a possible 16 types of different offenses (IQR $=1.0$ 3.0 , range $=1-9)$. The majority $(74.5 \%, n=181)$ indicated that they regretted one of the crimes that they had committed. Those who showed remorse reported more severe PTSD symptoms ( $M$ $=6.41, \mathrm{IQR}=0.0-9.0$ ) than those who indicated that they did not regret any crime that they had committed $(M=4.60, I Q R$ $=0.0-6.25), U=4,641.50, p=.038$.

Diagnostic criteria for PTSD were met by $13.5 \%(n=36)$ of the perpetrators and by $46.4 \%(n=52)$ of the interviewed survivors, $\chi^{2}(1, N=379)=48.04, p<.001$. Using the HSCL cut-off score of $1.75,41.4 \%(n=111)$ of the perpetrators and $46.4 \%(n=51)$ of the survivor sample were likely to demonstrate symptoms of depression. The rates of clinically significant anxiety were $35.8 \%(n=96)$ amongst perpetrators and $58.9 \%(n=66)$ amongst survivors, $\chi^{2}(1, N=380)=17.25$, $p<.001$. Almost one fifth of both groups were considered to be suicidal at the time of the interview. Differences in diagnostic criteria and symptom levels between the two groups are shown in Table 1.

Table 2 presents the 16 items that address the concept of reconciliation and the percentages of perpetrators and survivors who agreed to each item. Most participants agreed with items in the reconciliation attitude questionnaire. Nevertheless, some items displayed considerable variance and significant differences between perpetrators and survivors were observed on a number of issues.

The results of the linear regression analyses are presented in Table 3. Perpetrators with the highest PTSD scores were those who reported high levels of trauma confrontation, high levels of reconciliation, and who had not participated in murderrelated crimes (homicide or participation in a massacre). In the community sample, participants with the highest PTSD scores were women (compared to men), those who reported high levels of trauma exposure, and low levels of reconciliation. Women in the survivor sample had been exposed significantly more frequently to sexual violence compared to female perpetrators, $41.7 \%(n=30)$ versus $19.6 \%(n=18), \chi^{2}(1, N=164)=$ 9.53, $p=.003$. The explained variances of the models for the perpetrator and the survivor samples were $R^{2}=.21$ and $R^{2}=.31$.

The severity of depression symptoms in perpetrators was predicted by trauma exposure and participation in killing. Perpetrators with more severe depression symptoms reported high levels of trauma confrontation and had not participated in killings. In the community sample, the severity of depression was positively correlated with the number of experienced types of traumatic events and negatively correlated with the reconciliation score. In addition, gender had a significant influence on depression severity in the community sample, with women displaying more severe depression symptoms. The explained variances of the models for the perpetrator and the survivor sample were $R^{2}=.17$ and $R^{2}=.37$.

\section{Discussion}

Our results indicate that both groups-imprisoned Rwandan genocide perpetrators and genocide survivors-exhibit a considerable degree of psychiatric morbidity. Although there was no difference in depression symptom severity and risk of suicidality between perpetrators and survivors, the latter group scored higher than perpetrators in symptom severity of PTSD and anxiety.

Previous studies have consistently reported high rates of mental disorders, including high levels of PTSD and syndromal anxiety and depression amongst Rwandan genocide survivors (Brounéus, 2010; Schaal et al., 2011). The investigation of imprisoned genocide perpetrators, however, is unique and rates are thus hardly comparable with those in other studies of prisoners. Extreme pressure was exerted on the Rwandan population and ordinary people were transformed into killers, which resulted in 
Table 3

Simultaneous Multiple Regression Analyses for Posttraumatic Stress Disorder (PTSD) and Depression Separately for Perpetrators and Survivors

\begin{tabular}{|c|c|c|c|c|c|c|}
\hline \multirow[b]{2}{*}{ Variable } & \multicolumn{3}{|c|}{ Perpetrators $(n=269)$} & \multicolumn{3}{|c|}{ Survivors $(n=114)$} \\
\hline & B & $S E \mathrm{~B}$ & $b$ & B & $S E \mathrm{~B}$ & $b$ \\
\hline & \multicolumn{6}{|c|}{ PTSD severity } \\
\hline Gender & -1.65 & 0.99 & -.10 & -6.68 & 1.83 & $-.32 * * *$ \\
\hline Age & 0.02 & 0.04 & .03 & 0.06 & 0.08 & .07 \\
\hline School degree & 0.33 & 0.93 & .02 & 0.75 & 1.89 & .04 \\
\hline$N$ of traumatic events & 0.95 & 0.12 & $.47^{* * *}$ & 1.23 & 0.25 & $.41^{* * *}$ \\
\hline Reconciliation score & 0.17 & 0.08 & $.12^{*}$ & -0.30 & 0.14 & $-.17^{*}$ \\
\hline \multirow[t]{2}{*}{ Participation in killing } & -2.10 & 0.93 & $-.14^{*}$ & & & \\
\hline & \multicolumn{6}{|c|}{ Depression severity } \\
\hline Gender & -1.24 & 1.88 & -.07 & -5.84 & 1.68 & $-.30^{* *}$ \\
\hline Age & -0.10 & 0.05 & -.11 & 0.10 & 0.07 & .13 \\
\hline School degree & -0.99 & 1.10 & -.05 & 0.57 & 1.76 & .03 \\
\hline$N$ of traumatic events & 0.83 & 0.14 & $.35^{* * *}$ & 1.15 & 0.23 & $.41^{* *}$ \\
\hline Reconciliation score & -0.07 & 0.09 & -.04 & -0.48 & 0.13 & $-.29 * *$ \\
\hline Participation in killing & -3.73 & 1.11 & $-.21^{* * *}$ & & & \\
\hline
\end{tabular}

Note. Gender coded as female $=1$, male $=2$; school degree coded as no $=0$, yes $=1$; participation in killing coded as no $=0$, yes $=1$. For perpetrators, $R^{2}=.21$; for survivors, .31 for PTSD. For perpetrators, $R^{2}=.17$; for survivors, $R^{2}=.37$ for depression.

${ }^{*} p<.05 .{ }^{* *} p<.01 .{ }^{* * *} p<.001$.

a mass involvement in the genocide. The engagement in intense violence against others may be considered as traumatizing and may also cause symptoms of PTSD (Staub, 2006). Killing has often been described as being traumatizing (McNair, 2002). Killing someone may elicit horror and disgust. In the context of the genocide, many of the perpetrators may have felt forced to commit the crime and may thus have felt helpless with little control over their action. It is possible that the act of killing initially elicits a feeling of horror (due to the full realisation of the act) and as a consequence a feeling of helplessness (as the act cannot be undone). The present study, however, demonstrates that perpetrators less frequently met diagnostic criteria for PTSD compared to survivors ( $14 \%$ vs. $46 \%$ ). This might be explained by differences in trauma exposure, as survivors reported higher numbers of experienced types of traumatic events than perpetrators. Our findings indicate that a considerable portion of perpetrators displayed clinically significant depression symptoms $(41 \%)$. A number of factors may have contributed to the finding of severe depression symptoms amongst perpetrators: Imprisoned perpetrators have to cope with a number of ongoing stressors, including inmate overcrowding, inadequacy of prison health care services, malnutrition, and delays in bringing their cases to trial. Though many feel their sentence is unfair, according to the Gacaca system the accused has no right to appeal against the categorization of his or her crime (Kreitzer \& Jou, 2010), thereby reinforcing a sense of hopelessness. High levels of depression might also be related to social disruption. It is unclear to what extent the mental health status of the perpetrators can be attributed to the stress of imprisonment. More research is needed to clarify to what extent the high rates in this population are the causes or consequences of imprisonment (or both).

Our finding reveals that female gender constitutes a risk factor for the development of mental health problems in the survivor group. Nevertheless, this did not impact the severity of symptoms of PTSD and/or depression in the perpetrator group. The results of previous studies of samples of trauma survivors have demonstrated that women are more likely than men to develop symptoms of posttraumatic stress disorder (DiGrande et al., 2008) and depression (Thapa \& Hauff, 2005). According to Hapke, Schumann, Rumpf, John, and Meyer (2006), women do not have a higher vulnerability to PTSD in general, but more frequently experience sexual abuse and rape, event types that have been found to be associated with high rates of PTSD. Indeed, the findings of our study demonstrate that female perpetrators experienced sexual violence less frequently than female survivors ( $19.6 \%$ vs. $41.7 \%)$. Contrarily, meta-analytic results of Tolin and Foa (2006) suggest that the higher prevalence of PTSD among women cannot be attributed solely to a higher risk of sexual violence, but seem to cut across traumatic event categories. It is also possible that female perpetrators show lower levels of interpersonal sensitivity than female survivors. Low levels of interpersonal sensitivity have been found to be significantly associated with lower levels of PTSD symptom severity in female Chinese inmates (Huang, Zhang, Momartin, Cao, \& Zhoa, 2006). For perpetrators and survivors, neither age nor school degree were significantly associated with the severity of symptoms of PTSD and/or depression. 
In the present study, those survivors and perpetrators who reported a greater number of types of experienced traumatic events had higher levels of symptoms of PTSD and/or depression than those who reported fewer trauma experiences. Evidence on the dose effect supports the findings of other studies carried out in Rwanda, which have consistently demonstrated a significant relationship between the number of traumatic events and mental health (Neugebauer et al., 2009; Schaal \& Elbert, 2006). The present study demonstrates that such an additive effect of trauma exposure on symptoms of PTSD and depression not only applies to genocide victims, but also to perpetrators.

Our study found that attitudes towards reconciliation were associated with mental health symptoms in both study samples. Although a highly positive attitude towards reconciliation was a protective factor for psychiatric morbidity in the survivor group, it was a risk factor in the group of perpetrators. In the survivor sample, participants who had higher scores of reconciliation displayed less severe symptoms of PTSD and depression. That one's mental well-being has a positive impact on one's readiness to reconcile has also been stressed by Witvliet and colleagues (2004), who associated the difficulty to forgive others with depression and PTSD symptom severity. Cardozo Kaiser, Gotway, and Agani (2003) also found an association between orientations towards reconciliation and PTSD symptom severity. The results suggest that an improvement in mental health might also change attitudes towards reconciliation in genocide survivors. In the perpetrator sample, however, positive attitudes towards reconciliation were associated with more severe PTSD symptoms. It is possible that those perpetrators who suffer from PTSD are constantly reminded of their actions, which may lead to a feeling of repentance. Such a positive association between PTSD symptom severity and repentance of committed crimes was indeed found in our study. In the survivors, though, the pain of PTSD may instead lead to feelings of hatred and revenge.

We found that killing another person in war is a significant predictor of mental health symptoms in genocide perpetrators: Individuals who reported direct participation in killing were less susceptible to posttraumatic stress reactions and depression symptomatology than individuals who had not participated in killings. Only few perpetrators who participated in murder identified this experience as the most distressing event and reported that their response involved intense fear or helplessness (PTSD Criterion A according to the Diagnostic and Statistical Manual of Mental Disorders, 4th ed., DSM-IV; American Psychiatric Association, 1994). One might assume that a protective mechanism may prevent the perpetrator from becoming traumatized by self-initiated violent acts (Elbert et al., 2010). A possible physiological reward system involved in killing has been described by Van der Kolk, Greenberg, Boyd, and Krystal (1985). It may also be that more antisocial perpetrators were more likely to commit murder and also less likely to experience remorse-related distress.

Limitations of the study include its lack of application of an instrument that would have allowed us to determine the full diagnostic status of affective and anxiety disorders. As the instruments used were developed in Western cultures, diagnostic interpretations of cut-off scores have to be made carefully. Using the same instruments as in the present study, Ertl, Pfeiffer, Saile, Schauer, Elbert, and Neuner (2010) demonstrated that mental health assessments in African languages can produce reliable and valid data, but warrant caution in the unevaluated transfer of cutoff scores. Due to the cross-sectional and retrospective nature of the design, it is impossible to establish causal or temporal relationships between the different variables. Socially desirable responses can never be completely ruled out. The participation of respondents, however, was anonymous and questioning took place in an explicit research context, thereby reducing the likelihood of a strong bias. Finally, it may be possible that participants failed to recall or report traumatic experiences.

To our knowledge, this is the first study to report psychiatric morbidity in Rwandan genocide perpetrators. The findings of our study suggest that massive stress may have long-lasting effects if not addressed by clinical intervention and argue that there is a need for improved assessment and treatment capacities in Rwandan genocide survivors and perpetrators. A recent study demonstrated that symptoms of PTSD and depression can be effectively treated in this context (Schaal et al., 2009a). Effective treatments could prevent ongoing suffering, revictimization and recidivism, and may change attitudes towards reconciliation in genocide survivors.

\section{References}

Aguilar, M. I. (1998). The Rwanda genocide and the call to deepen Christianity in Africa. Eldoret, Kenya: Armecea Gaba Publications.

American Psychiatric Association. (1994). Diagnostic and statistical manual of mental disorders ( $4^{\text {th }}$ ed.). Arlington, VA: Author.

Basile, K. C., Arias, I., Desai, S., \& Thompson, M. P. (2004). The differential association of intimate partner physical, sexual, psychological, and stalking violence and posttraumatic stress symptoms in a nationally representative sample of women. Journal of Traumatic Stress, 17, 413-421. doi:10.1023/B:JOTS.0000048954.50232.d8

Bayer, C. P., Klasen, F., \& Adam, H. (2007). Association of trauma and PTSD symptoms with openness to reconciliation and feelings of revenge among former Ugandan and Congolese child soldiers. Journal of the American Medical Association, 298, 555-559. doi:10.1001/jama.298.5.555

Brewin, C. R., Andrews, B., \& Valentine, J. D. (2000). Meta-analysis of risk factors for posttraumatic stress disorder in trauma-exposed adults. Journal of Consulting and Clinical Psychology, 68, 748-766. doi:10.1037/0022006X.68.5.748

Brounéus, K. (2010). The trauma of truth telling: Effects of witnessing in the Rwandan Gacaca courts on psychological health. Journal of Conflict Resolution, 54, 408-437. doi:10.1177/0022002709360322

Cardozo, B. L., Kaiser, R., Gotway, C. A., \& Agani, F. (2003). Mental health, social functioning, and feelings of hatred and revenge of Kosovar Albanians one year after the war in Kosovo. Journal of Traumatic Stress, 16, 351-360. doi:10.1023/A:1024413918346

Derogatis, L. R., Lipman, R. S., Rickels, K., Uhlenhut, E. H., \& Covi, L. (1974). The Hopkins Symptom Checklist (HSCL): A self-report symptom inventory. Behavioral Science, 19, 1-15. doi:10.1002/bs.3830190102 
DiGrande, L., Perrin, M. A., Thorpe, L. E., Thalji, L., Murphy, J., Wu, D.....Brackbill, R. M. (2008). Posttraumatic stress symptoms, PTSD, and risk factors among lower Manhattan residents 2-3 years after the September 11, 2001 terrorist attacks. Journal of Traumatic Stress, 21, 264-273. doi: $10.1002 /$ jts. 20345

Elbert, T., Weierstall, R., \& Schauer, M. (2010). Fascination violence—on mind and brain of man hunters. European Archives of Psychiatry and Clinical Neuroscience, 260, 100-105. doi:10.1007/s00406-010-0144-8

Ertl, V., Pfeiffer, A., Saile, R., Schauer, E., Elbert, T., \& Neuner, F. (2010). Validation of a mental health assessment in an African conflict population. Psychological Assessment, 22, 318-324. doi:10.1037/a0018810

Foa, E. B., \& Tolin, D. F. (2000). Comparison of the PTSD Symptom ScaleInterview Version and the Clinician-Administered PTSD Scale. Journal of Traumatic Stress, 13, 181-191. doi:10.1023/A:1007781909213

Glas, G. (2006). Elements of a phenomenology of evil and forgiveness. In N. N. Potter (Ed.), Trauma, truth, and reconciliation-healing damaged relationships (pp. 171-202). Oxford, England: Oxford University Press.

Hapke, U., Schumann, A., Rumpf, H.-J., John, U., \& Meyer, C. (2006). Posttraumatic stress disorder: The role of trauma, pre-existing psychiatric disorders, and gender. European Archives of Psychiatry and Clinical Neuroscience, 256, 299-306. doi:10.1007/s00406-006-0654-6

Huang, G., Zhang, Y., Momartin, S., Cao, Y., \& Zhoa, L. (2006). Prevalence and characteristics of trauma and posttraumatic stress disorder in female prisoners in China. Comprehensive Psychiatry, 47, 20-29. doi:10.1016/j.comppsych.2005.04.004

Kohen, A., Zanchelli, M., \& Drake, L. (2011). Personal and political reconciliation in post-genocide Rwanda. Social Justice Research, 24, 85-106. doi:10.1007/s11211-011-0126-7

Kreitzer, L. M., \& Jou, M. K. (2010). Social work with victims of genocide: The alternatives to violence project (AVP) in Rwanda. International Social Work, 53, 73-86. doi:10.1177/0020872809348954

March, J. S. (1993). What constitutes a stressor? The "Criterion A" issue. In J. R. T. Davidson \& E. B. Foa (Eds.), Posttraumatic stress disorder: DSM-IV and beyond (pp. 37-54). Washington, DC: American Psychiatric Press.

McCullough, M. E., Worthington, E. L., \& Rachal K. C. (1997). Interpersonal forgiving in close relationships. Journal of Personality and Social Psychology, 73, 321-336. doi:10.1037/0022-3514.75.6.1586

McNair, R. M. (2002). Perpetration-induced stress. London, England: Praeger.

Marshall, G. N., Schell, T. L., Elliott, M. N., Berthold, S. M., \& Chun, C.-A. (2005). Mental health of Cambodian refugees 2 decades after resettlement in the United States. Journal of the American Medical Association, 294, 571-579. doi:10.1001/jama.294.5.571

Mollica, R. F., Wyshak, G., de Marneffe, D., Khuon, F., \& Lavelle, J. (1987). Indochinese versions of the Hopkins Symptom Checklist-25: A screening for the psychiatric care of refugees. American Journal of Psychiatry, 144, 497-500. Retrieved from http://ajp.psychiatryonline.org/

Nadelson, T. (1992). Attachment to killing. Journal of the American Academy of Psychoanalysis, 20,130-141. Retrieved from http://www.aapdp.org/
Neugebauer, R., Fisher, P. W., Turner, J. B., Yamabe, S., Sarsfield, J. A., \& Stehling-Ariza, T. (2009). Post-traumatic stress reactions among Rwandan children and adolescents in the early aftermath of genocide. International Journal of Epidemiology, 38, 1033-1045. doi:10.1093/ije/dyn375

Schaal, S., \& Elbert, T. (2006). Ten years after the genocide: Trauma confrontation and posttraumatic stress in Rwandan adolescents. Journal of Traumatic Stress, 19, 95-105. doi:10.1002/jts.20104

Schaal, S., Elbert, T., \& Neuner, F. (2009a). Narrative exposure therapy versus interpersonal psychotherapy - a pilot randomized controlled trial with Rwandan genocide orphans. Psychotherapy and Psychosomatics, 78, 298306. doi:10.1159/000229768

Schaal, S., Elbert, T., \& Neuner, F. (2009b). Prolonged grief disorder and depression in widows due to the Rwandan genocide. OMEGA-Journal of Death and Dying, 59, 203-219. doi:10.2190/OM.59.3.b

Schaal, S., Jacob, N., Dusingizemungu, J.-P., \& Elbert, T. (2010). Rates and risks for prolonged grief disorder in a sample of orphaned and widowed genocide survivors. BMC Psychiatry, 10, 55. doi:10.1186/1471-244X-1055 .

Schaal, S., Jacob, N., Dusingizemungu, J.-P., \& Elbert, T. (2011). Rates of trauma spectrum disorders and risks of posttraumatic stress disorder in a sample of orphaned and widowed genocide survivors. European Journal of Psychotraumatology, 2. doi:10.3402/ejpt.v2i0.6343

Scherrer, Ch. P. (1997). Ethnisierung und völkermord in Zentralafrika (Ethnicization and genocide in Central Africa). Frankfurt, Germany: Campus.

Sheehan, D. V., Lecrubier, Y., Sheehan, H., Amorim, P., Janavs, J., Weiller, E., Dunbar, G. C. (1998). The MINI-International Neuropsychiatric Interview (M.I.N.I.): The development and validation of a structured diagnostic psychiatric interview for DSM-IV and ICD-10. Journal of Clinical Psychiatry, 59, 22-33. Retrieved from http://www.psychiatrist.com/

Staub, E. (2006). Reconciliation after genocide, mass killing, or intractable conflict: Understanding the roots of violence, psychological recovery, and steps towards a general theory. Political Psychology, 27, 867-894. doi:10.1111/j.1467-9221.2006.00541.x

Staub, E., \& Pearlman, L. A. (2006). Advancing healing and reconciliation. In L. Barbanel \& R. Sternberg (Eds.), Psychological interventions in times of crisis (pp. 213-245). New York, NY: Springer-Verlag.

Thapa, S. B., \& Hauff, E. (2005). Psychological distress among displaced persons during an armed conflict in Nepal. Social Psychiatry and Psychiatric Epidemiology, 40, 672-679. doi:10.1007/s00127-005-0943-9

Tolin, D. F., \& Foa, E. B. (2006). Sex differences in trauma and posttraumatic stress disorder: A quantitative review of 25 years of research. Psychological Bulletin, 132,959-992. doi:10.1037/0033-2909.132.6.959

Van der Kolk, B., Greenberg, M., Boyd, H., \& Krystal, J. (1985). Inescapable shock, neurotransmitters, and addiction to trauma: Toward a psychobiology of post traumatic stress. Society of Biological Psychiatry, 20, 314-325. doi:10.1016/0006-3223(85)90061-7

Witvliet, C. V. O., Phipps, K. A., Feldmann, M. E., \& Beckham, J. C. (2004). Posttraumatic mental and physical health correlates of forgiveness and religious coping in military veterans. Journal of Traumatic Stress, 17, 269-273. doi:10.1023/B:JOTS.0000029270.47848.e5 